REMOA

\title{
EDUCAÇÃO E SAÚDE: SEMEANDO AÇÕES AMBIENTAIS JUNTO ÀS CRIANÇAS E CUIDADORES NO LAR ACALANTO - SANTA MARIA, RS
}

\author{
EDUCATION AND HEALTH: PLANTING TO ENVIRONMENTAL ACTIONS FOR CHILDREN AND \\ CAREGIVERS AT HOME ACALANTO - SANTA MARIA, RS
}

Rosane Seeger da Silva, Paulo Edelvar Corrêa Peres

\begin{abstract}
RESUMO
O presente estudo tem como propósito trabalhar ações de Educação Ambiental através do lúdico com as crianças que freqüentam e/ou recebem atendimento no Lar Acalanto, Casa de Apoio à Criança HIV/AIDS, na cidade de Santa Maria, RS. Por meio da realização deste projeto foi possível desenvolver junto às crianças que convivem com HIV/AIDS momentos de criatividade através de atividades lúdicas onde puderam expressar sentimentos e desejos de formas variadas, permitindo assim, que elas se sintam confiantes e valorizadas, além de proporcionar o conhecimento acerca dos temas que envolvem meio ambiente e cidadania incluindo a sua importância e o cuidado com as futuras gerações. Foi possível ainda, despertar e sensibilizar nestas crianças atitudes e idéias capazes de contribuir com a melhoria da qualidade de vida e do meio ambiente. Assim, deve-se enfatizar que as atividades lúdicas contribuem de modo significativo para o desenvolvimento das crianças, em termos cognitivos e sociais, bem como, provocando nestas uma mudança nos hábitos e atitudes em relação ao modo como se relacionam com o meio ambiente. A Educação Ambiental caracteriza-se como um processo dinâmico e contínuo, uma prática transformadora que permite uma compreensão das complexas relações entre a sociedade e a natureza. Assim torna- se indispensável sua incorporação em todos os níveis e modalidades de ensino formal e não formal, visto que é por meio da educação que o homem se transforma e, consequentemente, transforma a sociedade.
\end{abstract}

Palavras-chave: crianças, Educação Ambiental e Lúdico

\section{ABSTRACT}

This study aimed to work activities of Environmental Education through playful with children with HIV / AIDS, attending and / or receive care at the Home Acalanto, Home Child Support HIV / AIDS in the city of Santa Maria, RS. Through the implementation of this project were made possible with the children living with HIV / AIDS moments of creativity, the fun way where they could express feelings and desires in different ways, thus allowing them to feel confident and valued, and provide the knowledge about the issues involving the environment and citizenship including its importance and care of future generations. It can also wake up and raise children in these attitudes and ideas can contribute to improving the quality of life and the environment. Thus, it should be emphasized that the recreational activities contribute significantly to the development of children's cognitive and social terms as well as those causing 
a change in habits and attitudes towards how they relate to the environment. Environmental education is characterized as a dynamic process and keeps a transformative practice that allows an understanding of the complex relationships between society and nature. Thus it is essential to their incorporation at all levels and modes of teaching and non-formal, since it is through education that the man turns and thus transforms society.

Key-words: children, environmental education and Playful

\section{INTRODUÇÃO}

A Educação Ambiental destaca-se como tema transversal que permeia todas as ações, onde o respeito e o cuidado para com a vida e o meio ambiente são fundamentais, compreendendo homens, mulheres, jovens e crianças como sujeitos transformadores da realidade.

Essa forma de agir depende da educação, do conhecimento e da consciência que cada um possui em relação ao meio ambiente. É importante que essa consciência seja formada desde criança, através da Educação Ambiental, formando cidadãos responsáveis por suas ações. Se cada um fizer sua parte, tem-se um mundo mais sustentável, não somente para o presente, mas também para as futuras gerações.

De acordo com a Constituição Brasileira Federal de 1988, art. 225, 1o. parágrafo, item VI, o Poder Público deve "promover a educação ambiental em todos os níveis de ensino e a conscientização pública para a preservação do meio ambiente" (BRASIL, 1990).

A Política Nacional de Educação Ambiental, instituída pela Lei Federal no. 9.795, de 27 de abril de 1999, no Capítulo I, art. 1ㅇ, define a educação ambiental como:

Os processos por meio dos quais o individuo e a coletividade constroem valores sociais, conhecimentos, habilidades, atitudes e competências voltadas para a conservação do meio ambiente, bem como de uso comum do povo, essencial à sadia qualidade de vida e sua sustentabilidade.

No Rio Grande do Sul, a Assembléia Legislativa, institui a Lei no. 11.520 , de 03 de agosto de 2000, que procura atender assuntos de grande relevância ambiental, como a proteção da fauna, da flora, do solo, do ar, licenciamento ambiental, penalidades por infrações ambientais, poluição visual e sonora, municipalização da gestão ambiental, patrimônio genético, paleontológico e arqueológico, prevê a criação de mecanismos de estímulo e incentivos às boas práticas de preservação ambiental.

Já a Lei no. 11.730, de 09 de janeiro de 2002, dispõe sobre a Educação Ambiental, institui a Política Estadual de Educação Ambiental, cria o Programa Estadual de Educação Ambiental, e complementa a Lei Federal no. 9.795, de 27 de abril de 1999, no âmbito do Estado do Rio Grande do Sul. O conceito de Educação Ambiental é o mesmo adotado pela lei federal.

Assim como a lei federal, a estadual não recomenda a Educação Ambiental como uma disciplina, considera no artigo 2ㅇ: "Um componente essencial e permanente da educação estadual e nacional, devendo estar presente, de forma articulada, em todos os níveis e modalidades do processo educativo, em caráter formal e não formal".

A principal função da Educação Ambiental é a formação de cidadãos conscientes, preparados para a tomada de decisões e atuando na realidade sócio- ambiental, com um comprometimento com a vida, o bem estar de cada um e da sociedade. 
É de fundamental importância que a consciência ambiental, comece a ser trabalhada desde a infância, pois é nesta fase que sua personalidade se define e o seu processo de desenvolvimento está mais aberto à influência da ação educativa, tornando as crianças de hoje, futuros cidadãos responsáveis.

As atividades pedagógicas devem levar a criança a descobrir o prazer por observar, examinar e explorar o mundo que a rodeia, de modo a favorecer o interesse e o entusiasmo por formas originais de descobrir e de se relacionar com o mundo que o cerca. A Educação Ambiental infantil tem fundamental relevância na formação da consciência sobre a responsabilidade ambiental do ser humano, para que cada cidadão perceba a sua responsabilidade em relação aos valores de preservação e cuidado com o mundo que o cerca, levando esse conhecimento consigo e utilizando em toda sua vida.

Assim sendo, o presente estudo teve como propósito trabalhar ações ambientais através do lúdico junto às crianças e cuidadores, que freqüentam e/ou recebem atendimento junto ao Lar Acalanto, Casa de Apoio à Criança HIV/AIDS, na cidade de Santa Maria, RS.

Por meio da realização deste projeto foi possível proporcionar às crianças que convivem com HIV/AIDS momentos de criatividade, em que seus sentimentos e seus desejos foram expressos de formas variadas, permitindo assim, que elas se sintam mais tranqüilas, confiantes e mais valorizadas. Ainda, despertar e sensibilizar nestas crianças atitudes e idéias capazes de contribuir com a melhoria da qualidade de vida e do meio ambiente. Além de proporcionar o conhecimento acerca dos temas que envolvem meio ambiente e cidadania incluindo a sua importância e o cuidado com as futuras gerações. Foi possível ainda, despertar e sensibilizar nestas crianças atitudes e idéias capazes de contribuir com a melhoria da qualidade de vida e do meio ambiente.

E por acreditar que é preciso cada vez mais cedo e nos diferentes ambientes, conscientizar cada cidadão do seu papel na defesa e na preservação ambiental que apresenta-se esta proposta de trabalhar a Educação Ambiental de forma lúdica com as crianças e cuidadores do Lar Acalanto, Casa de Apoio à Criança com HIV/AIDS, em Santa Maria, RS.

\section{METODOLOGIA E DESENVOLVIMENTO DA PESQUISA}

Trata-se de uma pesquisa participativa, ou seja, neste tipo de pesquisa se estabelece relações comunicativas com as pessoas ou grupos investigados no intuito de serem mais bem aceitos, enquanto desempenham papel atuam nas soluções de problemas encontrados durante a pesquisa. Este tipo de pesquisa possibilita sensibilizar ao mesmo tempo em que se realiza a investigação.

O foco de atenção desta investigação são crianças e cuidadores que freqüentam e/ou recebem atendimento no Lar Acalanto, Casa de Apoio à Criança HIV/AIDS, na cidade de Santa Maria, RS.

O Lar Acalanto é uma organização não governamental e sem fins lucrativos fundada em 03 de setembro de 1999 e está situada na Avenida João Machado Soares, no.1340, Bairro Camobi, na cidade de Santa Maria, RS.

A proposta do presente estudo é trabalhar Educação Ambiental de forma lúdica, usando alternativas de ensino como oficinas, dinâmicas de grupo em forma seqüencial, jogos educativos, confecção de brinquedos recicláveis, entre outros. Questões como destino adequado do lixo, uso e conservação da água, higiene individual e do ambiente, alimentação 
saudável, poluição atmosférica, devastação das florestas, caça indiscriminada e demais formas dos assuntos pertinentes.

As atividades foram realizadas com crianças do sexo masculino e feminino, com idades entre 6 e 13 anos, usuários deste serviço.

A pesquisa foi realizada no segundo semestre de 2009, nos meses de agosto, setembro, outubro, novembro e dezembro. Os encontros foram desenvolvidos semanalmente, às quartas-feiras, no turno da tarde, com duração de uma a duas horas, nas quais as crianças eram estimuladas a manter a comunicação com o profissional e com as demais crianças e a partir deste laço de comunicação foram desenvolvidas as atividades propostas para o dia de trabalho. Cabe a este profissional estar atento à intensidade e duração das atividades, para que o praticante possa de acordo com sua condição física tirar o melhor proveito.

O trabalho no primeiro momento iniciou-se com uma pesquisa sobre os temas que seriam abordados, bem como, uma busca de materiais e organização das atividades que seriam trabalhadas. Atividades estas que deveriam proporcionar o diálogo e uma postura crítica das crianças com relação aos problemas ambientais. E ainda, possibilitar aos envolvidos,

oportunidades para desenvolver uma sensibilização aos problemas ambientais, propiciando uma reflexão a respeito desses problemas e a busca de soluções.

É importante que as crianças comecem, o mais cedo possível, a tomar consciência sobre a importância da preservação do meio ambiente em seus mais diversos aspectos. Desde a quantidade de comida que coloca no prato, para comer, sem desperdício; a forma como utiliza a água para tomar banho, escovar os dentes, lavar algo, até a utilização e o cuidado com os diversos utensílios domésticos do seu dia a dia.

Segundo Morin (2000, p.76): “É necessário aprender a estar aqui no planeta. Aprender a estar aqui significa aprender a viver, a dividir, a comunicar, a comungar; é o que se aprende somente nas culturas singulares". Os problemas ambientais são globais e para serem minimizados é preciso o envolvimento de todos, pois todos são habitantes do planeta e responsáveis pela sua conservação.

Após iniciou-se um trabalho de observação e conhecimento do grupo através de conversas informais, a fim de proporcionar um entrosamento com as crianças, familiares e cuidadores, conversações sobre os relacionamentos com a família, amigos, animais, plantas, valorização de todos os seres com os quais compartilham a vida, ponto de partida para um trabalho de educação ambiental.

Em seguida, apresentaram-se os objetivos do projeto e levantamento dos interesses das crianças. Ainda, uma dinâmica de apresentação onde cada criança teve a oportunidade de relatar sua realidade, suas dificuldades, seus conhecimentos sobre as questões ambientais.

Neste primeiro contato, percebeu-se que a temática era de interesse de todos, pois participaram com muito afinco e entusiasmo. Depois deste primeiro encontro, buscou-se trabalhar atividades que levassem as crianças a descobrir o prazer por observar, examinar e explorar o mundo que as rodeia, de modo a favorecer o interesse e o entusiasmo em descobrir e se relacionar com o mundo que a cerca. A programação destas atividades, sempre de forma flexível fomentando assim, a participação ativa das crianças.

A preocupação com o meio ambiente é atual e envolve toda a sociedade, quanto mais cedo o tema for abordado com as crianças, maiores as chances de despertar a consciência pela preservação, e para falar sobre Educação Ambiental com crianças é importante abordar assuntos que produzam resultados ao alcance delas.

Entre as atividades propostas, foi solicitada que as crianças desenhassem ou escrevessem o que 


\section{SILVA \& PERES, vol.(4), n4, p. 793-800, 2011. Monografias Ambientais ～(e-ISSN:2236-1308)}

REMOA

entendiam por meio ambiente. E surgiram respostas e desenhos significativos para o trabalho de sensibilização junto aos participantes. Os desenhos produzidos pelas crianças representam o meio ambiente natural, ou seja, sem as interferências do ser humano, um ambiente intocado pelo homem. Assim, percebe- se que as crianças agem e pensam como se estivessem fora do meio ambiente.

Também foram realizadas atividades em que se enfatizava a importância do auto-cuidado, da higiene pessoal entre outros assuntos pertinentes. Muitos aspectos da vida cotidiana surgiram, partindo da percepção das próprias crianças, como por exemplo, a questão do lixo - como o lixo é encarado no meio ambiente em que se vive, de que forma este pode prejudicar a saúde, o bem estar, no que prejudica a relação entre as pessoas, a questão do comportamento do homem, que interfere diretamente na relação de boa convivência com os demais de uma sociedade, entre outros assuntos abordados. Enfatizou-se a preocupação com o lixo, pois grande parte da população consome bem mais do que realmente é preciso para satisfazer as suas necessidades básicas.

Ainda, aproveitando este tema, as crianças realizaram um trabalho de pintura em tonéis, que serão utilizados como lixeiras, foram usadas as cores que identificam as lixeiras de coleta seletiva, verde, azul, amarelo, vermelho e marrom. As crianças realizaram esta atividade com muito afinco e entusiasmo. Estas lixeiras serão aproveitadas, auxiliando na segregação do lixo produzido na instituição, objetivando a valorização do trabalho realizado pelos educandos.

Ainda, foi trabalhada a higiene corporal, saúde bucal, importância da higienização das mãos e higiene dos alimentos. Atitudes que fazem parte da rotina diária de todos, para preservar a saúde e prevenir doenças. Os temas tratados: meio ambiente, água, lixo, higiene corporal, saúde bucal, higiene dos alimentos, etc., foram sempre tratados na perspectiva da responsabilidade individual e coletiva dos sujeitos.

O tema água foi trabalhado com o título Água no Planeta, usos, desperdícios, qualidade da água que se bebe, poluição, entre outros aspectos, procurando diagnosticar o grau de preocupação e esclarecimento dos educandos sobre estes temas. As crianças confeccionaram camisetas de papel pardo, onde cada criança teve a oportunidade de criar sua mensagem ou desenho para divulgação, ressaltando a importância do tema proposto.

Esta atividade foi bastante interessante, permitindo constatar que as crianças reconhecem o quanto a água é fundamental para garantir a sobrevivência de todos os seres vivos, assim como para manter a qualidade de vida.

Assuntos como a poluição, efeitos causados pela poluição do ar, aquecimento global, efeito estufa, mudanças climáticas, destruição da camada de ozônio e ainda, como combate aos desperdícios do dia a dia. Foram abordados com as crianças e estas convidadas a criar um grande painel intitulado como "Planeta Terra: minha casa".

Ainda, durante a realização do projeto criou-se um mural Ambiental, onde serão colocadas notícias, reportagens, tanto formal como informal, e trazer também uma miscelânea de informações referentes à educação, proteção, preservação, manutenção e recuperação ambiental, enfim fatos interessantes encontrados tanto pelas crianças como pelos seus cuidadores e demais funcionários da instituição, todos serão responsáveis por trazerem notícias para serem fixadas no mural e pela atualização do mesmo.

O mural proporcionou aprendizado, disseminação de conhecimentos e informações não só às crianças, mas também a todas as pessoas que circulam na instituição.

No decorrer dos encontros, a partir dos temas trabalhados, foi sendo elaborada uma cartilha de Educação Ambiental, a qual recebeu o título de Boas Práticas Ambientais: Cuidando 
do Planeta.

A cartilha é uma semente a ser lançada pela Educação Ambiental junto à instituição, Lar Acalanto, Casa de Apoio à Criança com HIV/AIDS, em Santa Maria, RS, na busca da criança verse como parte integrante da natureza, como auxílio para tratar e relacionar as questões ambientais e poder optar, quanto mais cedo possível, à aquisição de hábitos alimentares saudáveis visando uma melhor qualidade de vida com saúde e cidadania.

Ainda, alertar a respeito da falta de limite do homem com a natureza e com a saúde. O que se pretende é transmitir informação, conhecimento e sensibilização à criança e seus cuidadores através de trabalhos educativos, mostrando ser possível reencontrar-se o equilíbrio perdido entre a natureza e o homem, visto a acentuada queda da qualidade de vida que cresce a cada dia em seu cotidiano.

A cartilha apresenta uma abordagem sobre o meio ambiente, buscando despertar o cuidado e o respeito com o mesmo. Aborda também o tema lixo, trazendo alguns cuidados que devem ser tomados para que o lixo não prejudique o meio ambiente, prejuízos causados pelo lixo, a coleta seletiva, ainda uma tabela com os materiais recicláveis mais comuns no dia a dia e a decomposição do lixo.

Traz ainda, alguns tipos de poluição, aquecimento global, efeito estufa, mudanças climáticas, desmatamento e água e curiosidades e como economizar este recurso. Aborda o tema higiene, enfatizando a higiene pessoal, bucal e dos alimentos, que são atitudes que fazem parte do dia a dia de todos, para preservar a saúde e prevenir doenças.

Ao longo do cumprimento de todas as etapas do projeto constatou-se que os objetivos iniciais tinham sido alcançados, ao observar a mudança postural e de atitudes no contingente envolvido, como a observação crítica dos ambientes que freqüentam (casa, escola, vias públicas, etc.) e a mudança interior de cada um passando a agir nesses locais.

Os resultados obtidos na aplicação do projeto, levaram à conclusão de que tem-se, a partir de então, mais atores sociais envolvidos na problemática ambiental e que darão continuidade à causa da preservação ambiental, exercendo de forma plena sua cidadania, sendo eticamente corretas com a natureza e, por conseqüência, com seu semelhante.

A educação ambiental promoveu a sensibilização quanto à importância da conservação e preservação do ambiente tornando-os capazes de repassar seus conhecimentos teóricos e práticos adquiridos durante a realização do projeto.

\section{CONCLUSÃO}

Verifica-se a importância de cada vez mais ações de conscientização nas escolas, nas instituições e em diferentes ambientes se fazerem necessárias, para que não aconteça o fracasso ou grandes catástrofes como as que têm ocorrido para que algo seja feito. É possível mudar a realidade dos problemas ambientais se cada um fizer a sua parte.

A realização deste trabalho é de suma importância, pois permite que as crianças percebam seu valor, tornem-se parte integrante do meio ambiente, e sujeitos ativos da sociedade. Difundindo conhecimentos e tornando cidadãos responsáveis pelas suas atitudes perante a sua casa, o "Planeta Terra".

É de fundamental importância que a consciência ambiental, comece a ser trabalhada desde a infância, pois nesta fase que sua personalidade se define e seu processo de desenvolvimento está mais aberto à influência da ação educativa, tornando as crianças de hoje, futuros 
cidadãos responsáveis.

Pode-se julgar o trabalho gratificante, pois, além da satisfação das crianças, conseguiu-se finalizar todas as atividades propostas, chegando ao resultado desejado, que foi o de sensibilizar as crianças e cuidadores sobre o que se passa diariamente e como fazer para melhorar o meio em que vive-se, prestando a atenção nas ações para com os outros e para com o meio ambiente.

Espera-se que essas crianças sejam multiplicadoras dos temas abordados, sensibilizando, assim, as pessoas com as quais convivem da necessidade de preservar seu meio ambiente.

\section{REFERÊNCIAS BIBLIOGRÁFICAS}

ALVES, Rubens. A alegria de brincar. São Paulo: Ares Poéticos, 1994.

BRASIL. Constituição (1988). Constituição: República Federativa do Brasil. Porto Alegre: Ordem dos Advogados do Brasil, Estado do Rio Grande do Sul, 1988. BRASIL. Política Nacional de Educação Ambiental. Brasília, 1999.

BRASIL. Lei Federal n.o 6938 de 31 de agosto de 1981. In: Legislação Brasileira do Meio Ambiente. Organizado por Rogério Rocco. RJ: DP\&A, 2002.

BRASIL. MINISTÉRIO DA SAÚDE. Programa Agenda Ambiental. Brasília - DF: Ministério da Saúde, julho de 2003.

BRASIL. MINISTÉRIO DA SAÚDE. Departamento de Atenção Básica. Saúde Bucal. Brasília - DF: Ministério da Saúde, 2006.

CANALKIDS. Disponível em: <http//:www.canalkids.com.br>. Acesso em: 09 out. 2009.

CRIANÇAECOLÓGICA. Teatro. Disponível em: <http//:www.criancaecologica.sp.gov.br>. Acesso em: 15 set. 2009.

DINELLO, Raimundo. Expression Ludico Creativa. Montivideo: Nuevos Horizontes, 2002.

FAJARDO, Elias. Se cada um fizer sua parte... ecologia e cidadania. Rio de janeiro: Senac Nacional, 1998.

FREIRE, P. Pedagogia da Autonomia: saberes necessários à prática educativa. Rio de janeiro: Paz e Terra, 1996.

FONSECA, Eneida Simões da. Atendimento escolar no ambiente hospitalar. São Paulo: Memnon, 2003.

KISHIMOTO, Tizuko Mochida. Brinquedo e Brincadeira: usos e significados dentro de diferentes contextos culturais. In: SANTOS, Santa Marli Pires dos (org.). Brinquedoteca: O lúdico em diferentes contextos. 4 ed. Petrópolis, RJ: Vozes, 1997.

LEEF, H. Saber ambiental sustentabilidade, racionalidade, complexidade, poder. Petrópolis, RJ, Vozes, 2001.

LIXO.COM.BR. Consciência sócio ambiental. Disponível em: <http//:www.lixo.com.br>. Acesso em: 09 out. 2009.

MEDINA, Nana; SANTOS, Elizabeth. Educação Ambiental: uma metodologia participativa de formação. Petrópolis, RJ: Vozes, 1999.

MORIN, E. Os sete saberes necessários à educação do futuro. São Paulo, Cortez, 2000.

MULLER, Andréia G. Brincando com a Educação Ambiental através dos sentidos: uma vivência na pré- 
SILVA \& PERES, vol.(4), n4, p. 793-800, 2011.

\section{Monografias Ambientais ～(e-ISSN: 2236-1308)}

REMOA

escola. Monografia de Especialização em Educação Ambiental. Santa Maria: UFSM, 2005.

MULLER, Jackson. Educação Ambiental: diretrizes para a prática pedagógica. Porto Alegre, 2000.

PASSOS, C; SILVA, Z. Eu Gosto de Ciências: Programa de saúde. 3ạ. Série. São Paulo: Companhia Editorial Nacional, 1994.

REIS, Tatiana Regina Sandy. Agricultura sustentável - mundo sustentável. Disponível em: <http//:www.agriculturaorganica.xpg.com.br> Acesso em: 9 out. 2009.

SANTOS, Santa Marli Pires dos. O lúdico na formação do educador. Rio de Janeiro: Vozes, 1997.

SANTOS, Santa Marli Pires dos (org.). Brinquedoteca: A criança, o adulto e o lúdico. Petrópolis, RJ: Vozes, 2000.

UNIVERSIDADE DA ÁGUA. Disponível em: <http//:www.uniagua.org.br>Acesso em: 15 set. 2009. 